\title{
Performance Analysis of Homemade Recorder
}

\author{
Lin Chen \\ Educational Science College of Chongqing Normal University \\ chenlin_800123@163.com
}

Keywords: Homemade recorder; Sound quality; Analyze; Sound devices 744T; Comparative analysis

\begin{abstract}
The recording technology is widely used in today's society, People has higher requirement for recording quality. At the same time, Professional tape recorder is becoming more and more expensive. How to use limited conditions for high quality audio recording file became the most people of a kind of expectations. When choosing recording products, people may form such a view: the higher the price, the better the recording quality; and vice vesa. Therefore, when we buy recording products, usually we are willing to pay a higher price for professional recording devices. Actually, the recording quality of cheap recorders is comparable to that of professional recorders if we use the correct recording method. Using waste computer homemade tape recorder, Can be used for high quality recordings? To this, Our objective of homemade recorder test, Subjective evaluation on audio effect. To prove that the homemade recorder is able to perform high quality recordings. This study used again for homemade recorder and waste resources .

By using a professional recorder (744T) and its homemade recorder, the Educational Technology Department of Chongqing Normal University completed the recording and post-production for the national classic public courses several times. Both recorders are up to the national standard for all audio indexes. We tested and analyzed the performance of the homemade recorder, which proved it could be used for high quality recording.
\end{abstract}

An international-recognized evaluation for devices related to visual or audio sense should be a comprehensive evaluation covering both subjective and objective views. In this study, when we evaluate the performance of the recorders, we mainly use objective tests. Therein, the subjective evaluation means grading the recording effect of different recorders through closed-eye listening, while the objective tests means testing the performance indexes of recorders by using related devices and instruments.[1]

The homemade recorder is a Pentium four computer with a audio card, and its recording is achieved through a audio software COOLEDIT. The operating principle is as follows: the audio card converts an analog audio signal into a digital audio signal, and then the audio-edit software COOLEDIT is used for recording and storing the audio in the hard drive. The homemade recorder is based on Windows ${ }^{\circledR}$ operating platform, and it can do the post-editing for stored digital audio signals. Thant means the homemade recorder has the function of recording and editing.[2]

This objective test covers the tests for frequency response, distortion factor and signal-to-noise ratio (SNR) of recorders. During the tests. [3] we only change the test objects and other conditions are kept constant.

We use a hard-drive based recorder (American Sound devices 744t) as the reference object. Featured portability and high-quality recording, this recorder is a fashionable and well-known one in 
the market, but its price is over 30,000 RMB. In order to prove that the homemade recorder can be used for high-quality recording, we will compare these two recorders to minimize the test deviation.[4]

\section{Frequency Response Test}

The instruments used for testing frequency response are a low-frequency signal generator (XD-2A series), a digital oscilloscope (SDS-1102DL) and several connection cables. The connection is as shown in figure1.[5]

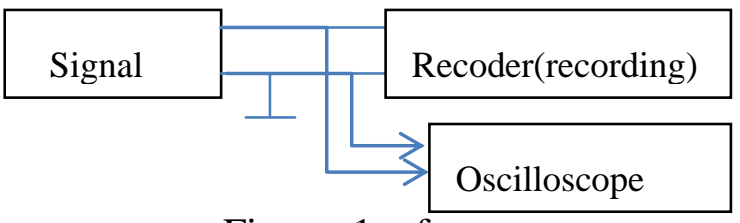

Figure. 1 frequency response test

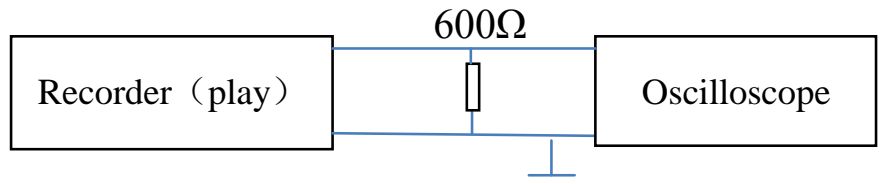

Figure. 2 frequency response

The figure 1. shows how to test the peak-to-peak value of input signal at different frequencies during the recording. The detailed operation is as follows.

Connect the homemade recorder and instruments as shown in the figure 1. In order to make the test results comparable, before input the signal we set the recorder's sampling frequency to be 92 $\mathrm{Khz}$ and digitalizing bit to be 16 bit. According to the international standard, we keep the peak-to-peak value around $1 \mathrm{~V}$, and write down the test results. Then cut off the power and switch the test object to 744T recorder, repeat the above operating procedure.[6] (The results are showing in tables 1 and 2.

After test the peak-to peak value of the input signal, test that of the output signal according to figure 2 .

First connect the homemade recorder with a $600 \Omega$ resistance at the output end as shown in the above figure 2, and then play the recorded input signals at different frequency bands. Use oscilloscope to measure the peak-to peak value of output signals at different frequency bands, and write down the results. Then switch the test object to $744 \mathrm{~T}$ recorder, repeat the above operating procedure. [7] The test results are as follows:

Table 1 peak-to-peak value of the homemade recorder signal

\begin{tabular}{|c|c|c|c|c|c|c|c|c|c|}
\hline $\mathrm{F}(\mathrm{Hz})$ & 20 & 30 & 50 & 100 & 200 & 400 & 800 & 1000 & 2000 \\
\hline $\mathrm{V}_{\text {ip-p }}(\mathrm{V})$ & 1.04 & 1.04 & 1.04 & 1.04 & 1.04 & 1.04 & 1.04 & 1.04 & 1.04 \\
\hline $\mathrm{V}_{\text {op-p }}(\mathrm{V})$ & 2.52 & 2.80 & 2.88 & 3.08 & 3.04 & 3.08 & 3.08 & 2.80 & 3.04 \\
\hline $\mathrm{F}(\mathrm{Hz})$ & 4000 & 6000 & 8000 & 10000 & 12000 & 14000 & 16000 & 18000 & 20000 \\
\hline $\mathrm{V}_{\text {ip-p }}(\mathrm{V})$ & 1.04 & 1.04 & 1.04 & 1.04 & 1.04 & 1.04 & 1.04 & 1.04 & 1.04 \\
\hline $\mathrm{V}_{\text {op-p }}(\mathrm{V})$ & 3.04 & 3.12 & 3.12 & 3.00 & 3.12 & 3.12 & 3.04 & 3.12 & 2.64 \\
\hline
\end{tabular}

Table 2 peak-to-peak value of the 744t recorder signal

\begin{tabular}{|c|c|c|c|c|c|c|c|c|c|}
\hline $\mathrm{F}(\mathrm{Hz})$ & 20 & 30 & 50 & 100 & 200 & 400 & 800 & 1000 & 2000 \\
\hline $\mathrm{V}_{\text {ip-p }}(\mathrm{V})$ & 1.04 & 1.04 & 1.04 & 1.04 & 1.04 & 1.04 & 1.04 & 1.04 & 1.04 \\
\hline $\mathrm{V}_{\text {op-p }}(\mathrm{V})$ & 4.04 & 3.96 & 4.00 & 3.88 & 3.96 & 4.00 & 4.00 & 4.00 & 4.00 \\
\hline $\mathrm{F}(\mathrm{Hz})$ & 4000 & 6000 & 8000 & 10000 & 12000 & 14000 & 16000 & 18000 & 20000 \\
\hline $\mathrm{V}_{\text {ip-p }}(\mathrm{V})$ & 1.04 & 1.04 & 1.04 & 1.04 & 1.04 & 1.04 & 1.04 & 1.04 & 1.04 \\
\hline $\mathrm{V}_{\text {op-p }}(\mathrm{V})$ & 4.00 & 4.08 & 4.08 & 4.08 & 4.04 & 4.04 & 4.04 & 4.04 & 4.00 \\
\hline
\end{tabular}


We graphed the magnitude-frequency characteristic of frequency response based on the two tables above. The horizontal-coordinate represents frequency, while the vertical -coordinate the corresponding peak-to-peak value of voltage. The result shows in figure 3-1 and figure 3-1.

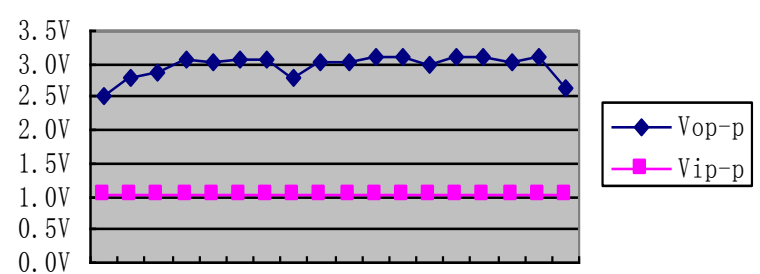

$v^{20.6020}$

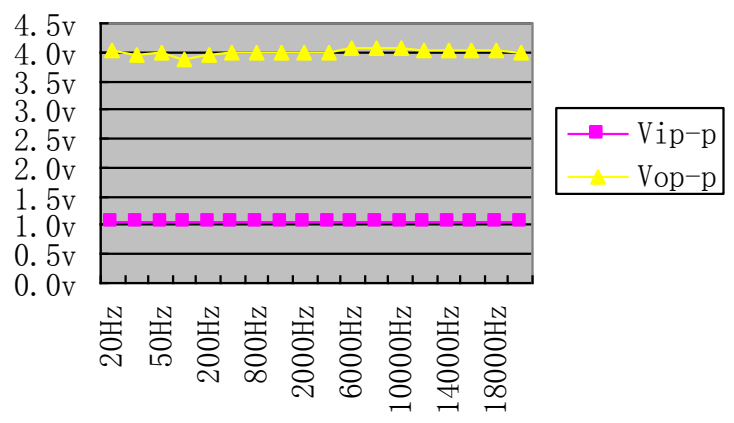

Figure. 3-2 frequency response of 774t recorder

Figure. 3-1 frequency response of homemade recorder

We can tell from figure 3-1 and figure 3-1, the frequency responses between the homemade recorder and 744T recorder are different in part, but overall they are at the same level.

\section{Distortion Factor Test}

The instruments we use to test the recorders' distortion factors are a low-frequency signal generator (XD-2A series), a digital oscilloscope (SDS - 1102DL) and a distortion meter (ZN4116). [8]

The test instrument itself has distortion, so before the distortion factor test, we need to test the distortion factor of the input signal as shown in figure 4.

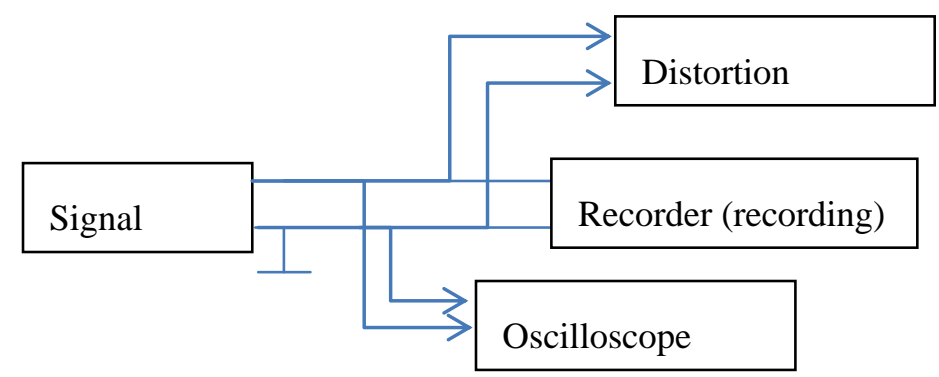

Figure. 4 Distortion Factor Test 1

This figure shows how to test distortion factor of the input signal:

Connect the homemade recorder as shown in this figure and switch on the power. In order to make the test results comparable, before input the signal we set the recorder's sampling frequency to be $92 \mathrm{Khz}$ and digitalizing bit to be 16 bit. During the testing process we should keep all joints in good contact, adjust the signal generator and distortion meter accordingly, record the distortion factors of the input signals at different frequencies. Then switch the test object to 744T recorder, repeat the above operating procedure.[9] (The results are showing in tables 3 and 4)

After test the distortion factor of the input signal, test that of the output signal according to figure 5. 


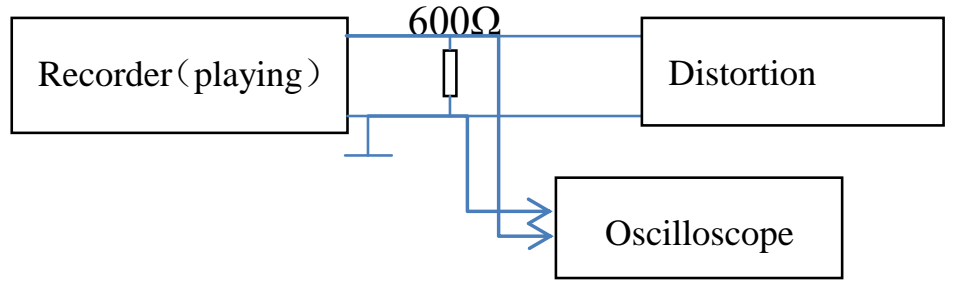

Figure. 5 Distortion Factor Test 2

First connect the homemade recorder as shown in the above figure, and then play the recorded signals at different frequency bands. Use distortion meter to measure the distortion factors of output signals at different frequency bands, and write down the results. Then switch the test object to 744T recorder, repeat the above operating procedure. The test results are as follows:

Table 3 Distortion Factor of Homemade Recorder

\begin{tabular}{|c|c|c|c|c|c|c|}
\hline $\mathrm{F}(\mathrm{Hz})$ & 50 & 100 & 200 & 400 & 800 & 1000 \\
\hline Input (\%) & 0.18 & 0.24 & 0.30 & 0.30 & 0.24 & 0.24 \\
\hline Output (\%) & 0.90 & 0.90 & 0.66 & 0.66 & 0.66 & 0.66 \\
\hline $\mathrm{F}(\mathrm{Hz})$ & 2000 & 4000 & 8000 & 10000 & 14000 & 20000 \\
\hline Input (\%) & 0.30 & 0.36 & 0.42 & 0.48 & 0.51 & 0.60 \\
\hline Output (\%) & 1.02 & 1.02 & 1.02 & 0.66 & 1.02 & 0.96 \\
\hline
\end{tabular}

Table 4 Distortion Factor of 744T Recorder

\begin{tabular}{|c|c|c|c|c|c|c|}
\hline $\mathrm{F}(\mathrm{Hz})$ & 50 & 100 & 200 & 400 & 800 & 1000 \\
\hline Input (\%) & 0.15 & 0.24 & 0.30 & 0.30 & 0.24 & 0.24 \\
\hline Output (\%) & 0.42 & 0.48 & 0.42 & 0.48 & 0.54 & 0.72 \\
\hline $\mathrm{F}(\mathrm{Hz})$ & 2000 & 4000 & 8000 & 10000 & 14000 & 20000 \\
\hline Input (\%) & 0.30 & 0.36 & 0.42 & 0.48 & 0.51 & 0.60 \\
\hline Output (\%) & 1.08 & 1.38 & 1.14 & 1.14 & 1.26 & 1.14 \\
\hline
\end{tabular}

We can tell from tables 3 and 4 that the homemade recorder and 744T hard-drive based recorder exceed in distortion factor at different frequency bands. The minimum output distortion of the homemade recorder is $0.66 \%$, and its maximum one is $1.02 \%$. The minimum output distortion of $744 \%$ recorder is $0.42 \%$, and its maximum one is $1.38 \%$. They are differential in part, but overall they are neck and neck.

\section{SNR Test}

This SNR test is done through the analysis of the recorded sound's waveform.

(1).Analysis for the SNR of the homemade recorder

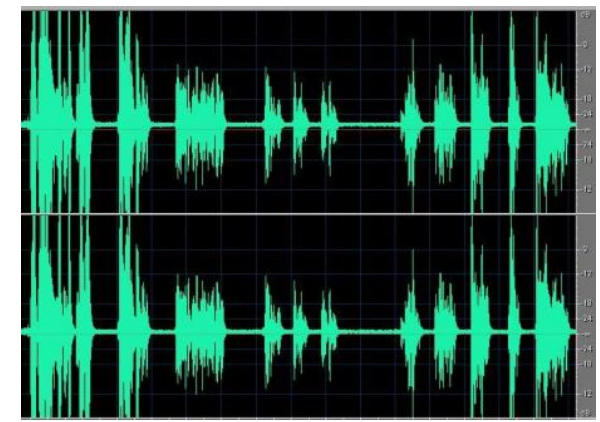

Figure. 6-1 signal with sound source

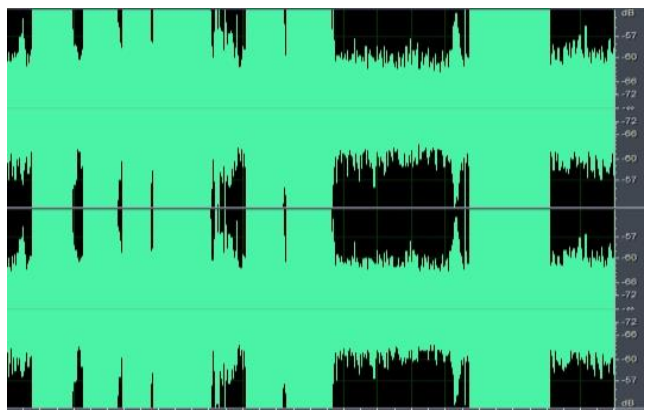

Figure. 6-2 no input signal

Figure. 6 audio oscillograph of homemade recorder 
From the graphs 1 and 2 of figure 6, we can calculate the SNR of the sound recorded by the homemade recorder. That is, $\mathrm{S} / \mathrm{N}=-9 \mathrm{~dB}-(-57 \mathrm{~dB})=48 \mathrm{~dB}$.

(2).Analysis for the SNR of 744T recorder

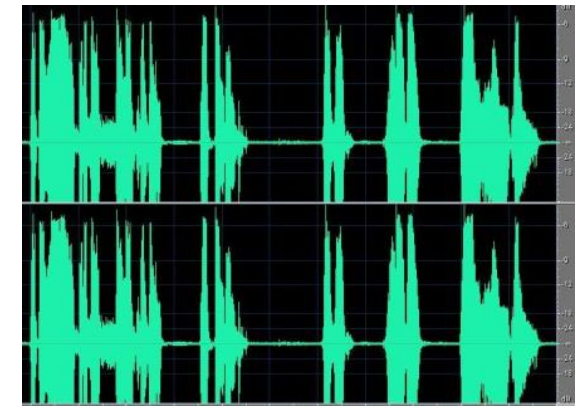

Figure. 7-1 signal with source sound

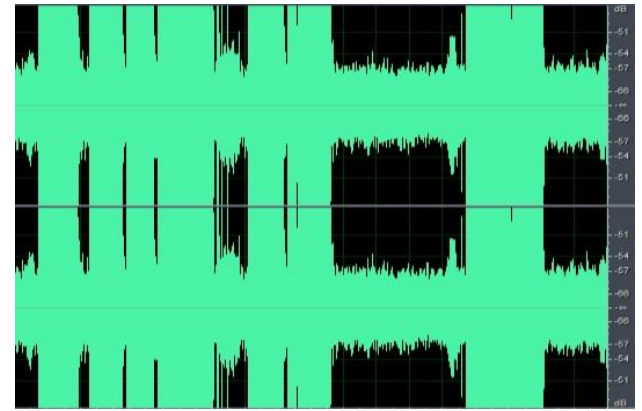

Figure. 7-2 no input signal

Figure. 7 audio oscillograph of 744T recorder

From the graphs 1 and 2 of figure7, we can calculate the SNR of the sound recorded by 744T recorder. That is, $\mathrm{S} / \mathrm{N}=-6 \mathrm{~dB}-(-57 \mathrm{~dB})=51 \mathrm{~dB}$.

From the waveform analysis for two recorders, we can tell the differential SNR between the homemade recorder and $744 \mathrm{~T}$ recorder is $3 \mathrm{~dB}$.

By comparing the test results of frequency response, distortion factor and signal to noise ratio (SNR), we conclude the performance of the homemade recorder is comparable to that of the 744T hard-drive based recorder, and can be used for high-quality recording.

\section{Summary}

In 2013, for the waste phenomenon happened in catering sector, the relevant departments of the state put forward the policy of austerity against waste. In fact, waste phenomena not only happened in the catering sector, but also occur in many aspects of our daily life. [10] There is unnecessary waste in public and private purchases. As for the recording device, if we make such a recorder by ourselves, it can save money and do a high-quality recording as well. It is fully capable of doing the job of a professional recorder. For the institutions short of fund, making such a recorder can meet the needs; even for the institutions with sufficient funds, it can save expenses. Making such a recorder, not only meets our own needs, but also promotes frugality custom and reuses waste resources, which to maximize the use of resources. This action, which is beneficial to all people, is worth promoting and being made universal.

\section{References}

[1]W.J. Dong: The Multimedia Technical Basis and Practice (Tsinghua University Press,China 2013).

[2]Y. Shen: 2014 New Developments in Electronic Technology (Science Press, China 2014).

[3]L.Zhang, Y.P. Wang and J.J. Zhou: China's Medical Education Technology, Vol. 27 (2013),p42-44 [4]W. Li, Z.Q. Hu, Q.F. Shang and Y.C. Qi: Power System Correspondence, Vol. 30 (2009) ,p.64-71

[5]K.J. Chen: Electroacoustic Technology,(1980),p.7-16 
[6]Z.B. Li: Performance Equipment with Science,Vol. 9 (2005), p22-25

[7]L.Z. Su: Journal of Shangyang University, Vol. 3 (2006) No.2,p72-74

[8]M.Y. Zhou: Journalist Cradle, (2006),p49-50

[9]Z.B. Wang: Scientific Information Development \& Economics, Vol. 15 (2005) No.13,p.251-252

[10] Information on http://wenku.baidu.com/view/39d4189b51e79b89680226a1.html 